\title{
How State and Protester Violence Affect Protest
}

\section{Dynamics}

\author{
Zachary C. Steinert-Threlkeld; Alexander Chan ${ }^{\dagger}$ and Jungseock Joo ${ }^{\ddagger}$
}

\begin{abstract}
How do state and protester violence affect whether protests grow or shrink? Previous research finds conflicting results for how violence affects protest dynamics. This paper argues that expectations and emotions should generate an n-shaped relationship between the severity of state repression and changes in protest size the next day. Protester violence should reduce the appeal of protesting and increase the expected cost of protesting, decreasing subsequent protest size. Since testing this argument requires precise measurements, a pipeline is built that applies convolutional neural networks to images shared in geolocated tweets. Continuously valued estimates of state and protester violence are generated per city-day for 24 cities across five countries, as are estimates of protest size and the age and gender of protesters. The results suggest a solution to the repression-dissent puzzle and join a growing body of research benefiting from the use of social media to understand subnational conflict.
\end{abstract}

Keywords. Protest, repression, social media, computer vision.

Supplementary material for this article is available in the appendix in the online addition.

Replication files are available in the JOP Data Archive on Dataverse.

This version is accepted at the Journal of Politics as of 05.05.2021. Estimated publication date is April 2022.

\footnotetext{
*zst@luskin.ucla.edu

†alexander.chan@ucla.edu

†jjoo@comm.ucla.edu
} 
Though formal and empirical research has established the importance of large protests (DeNardo, 1985, Wouters and Walgrave, 2017), their dynamics remain less understood. For example, Biggs (2003) argues for a positive feedback loop but does not specify when an initial protest is more likely to generate that process, and built environments or electoral fraud encourage protest participation (Tucker, 2007, Zhao, 1998). Empirical investigations have generated contradictory results for decades, making repression and protest dynamics an enduring puzzle (Davenport, 2007). Studying these dynamics has been difficult because existing methodologies generate coarse (ordinal) estimates of violence and have difficulty measuring the size of protests, possibly contributing to the literature's conflicting results.

How violence affects protest dynamics depends on its source and severity. When it comes from the state, low amounts of violence mobilize more protesters while high amounts demobilize them, creating an n-shaped relationship between state violence and subsequent protest size. Lower than expected costs to protest and emotional backlash generate the increase in protest size, while higher than expected costs and dispiriting emotions shrink it. Protester violence always leads to smaller protests because it decreases the appeal of protesting and increases the probability of state violence.

In addition to explaining the importance of the source and severity of violence, this paper improves the measurement of violence and protest size with new methodology (computer vision) applied to large data (millions of geolocated tweets containing images). A convolutional neural network $(\mathrm{CNN})$ is developed to recognize protest images. Of 42.6 million tweets from protest waves across five countries, 4.6 million contain an image. Approximately 115,000 of these images likely contain a protest. A second CNN generates binary and continuous measures of state and protester violence; these classifiers outperform Google Vision, a thirdparty CNN. This scene classifier is complemented with a third CNN, a face classifier. This classifier estimates the gender and age of each face, allowing us to control for well-known correlations between these demographic features and protest participation (Nordås and Davenport, 2013, Schaftenaar, 2017). Summing faces in protest images generates estimates of 
protest size, and extensive corroboration shows that these estimates are consistent with actual protest size. This pipeline generates daily estimates of the size of protest, the severity of state and protester violence continuously valued from $[0,1]$, and potential confounds for twenty-four cities in five countries

The next section explains how state and protester violence should affect protest size. After, detail on measuring and validating the concepts is provided. Then we explain how the concepts are measured and validate the classifier estimates. The penultimate section presents results and a battery of robustness checks. The conclusion suggests directions for future research. ${ }^{1}$

\section{Protest Dynamics}

Protesters want to join a large protest since they have larger net benefits because the probability of suffering repression is lower and the probability of policy change higher. Costs and benefits are uncertain a priori, however, so individuals use realized state and protester violence to calculate their payoffs (Shadmehr and Bernhardt, 2011). State violence causes different responses depending on its severity, generating an n-shaped relationship between it and subsequent protest size. Protester violence should always decrease protest size because it decreases the consumption benefit of protest while increasing the probability of repression.

\section{The Importance of Large Protests}

Three assumptions lead to the conclusion that large protests are more likely to change policy than small ones. If (1) the purpose of a protest is to convince political leaders to change a policy, (2) a leader cares about the median voter (Downs, 1957) or his or her winning coalition exhibits some response to the median person (Bueno de Mesquita et al., 2003), and (3) a large protest's policy preference is closer to the median individual than a small one's, then a large protest is more likely to change policy than a small one.

Protest size matters regardless of a country's political institutions. In democracies, voting

$1 \quad$ The empirical data has been successfully replicated by the JOP replication analyst. 
is the most common method of policy change but occurs infrequently. Protests, however, can occur at any time and usually have a clear policy goal (Battaglini, 2017), and they provide an additional outlet for revealing pressing sentiments. While protest is unlikely to change an autocrat's policy, it nonetheless provides a key signal of discontent to which a government can respond (Bratton and Walle, 1992). This signal is especially pertinent if opinion polling is unreliable (Robertson, 2007) or the media are not free (Qin, Strömberg and Wu, 2017).

This argument holds without assuming a leader aims for the median individual's policy preference. If a leader only desires to stay in power and a large protest means the probability of remaining in power is lower than the leader previously believed, a large protest is still more likely to lead to policy change than a small one. Though a regime should become less responsive to protests as its selectorate shrinks (Bueno de Mesquita et al., 2003), the importance of large protests increases inversely with the size of the selectorate since other mechanisms of policy change are foreclosed. This theory should therefore apply in a wide range of regimes such as rentier states, single-party regimes, and those with low Polity scores. While a large protest is not necessarily successful, almost all successful protests are large.

\section{State Violence}

State violence at protests should generate an n-shaped relationship via two mechanisms. ${ }^{2}$ First, how protesters and bystanders respond to repression depends on its severity relative to expectations, not an absolute level. If individuals protest when the expected benefit outweighs the expected cost and the probability of suffering repression affects expected cost (Tullock, 1971), then individuals decide to mobilize based on some expectation of harm. If the realized probability of harm is lower than the value an individual used in their personal calculation, then there will be bystanders who now expect to benefit from protesting. So long as the repression is not larger than expected for a larger number of those already protesting, repression can generate growth in protest size. If, however, repression is more severe than expected, more protesters will demobilize than bystanders mobilize, and protest

2 "State violence" refers to what others call "protest policing" (Earl et al., 2013). 
size decreases. This relative expectation mechanism operates similarly to expectations about protester identity in information signalling models (Lohmann, 1994).

Second, repression triggers reflexive emotional responses that can cause more or fewer people to mobilize, depending on the emotions triggered (Jasper, 2011). When repression generates emboldening emotions such as anger, joy, or pride, protesters are more likely to persist and bystanders are more likely to mobilize. Anger incites a desire to confront the agents committing repression and facilitates blame attribution against the state. Joy reflects pleasure as protesters sense progress towards their policy goal. Pride enhances feelings of self-worth and belonging, especially in contrast to "bad" state agents (Pearlman, 2013).

Repression can also trigger dispiriting emotions such as fear, sadness, and shame, causing protest size to decrease. A fearful protester is more likely to cease protesting in order to escape the threat of repression. A sad one has determined that the current policy cannot be changed by individual action. Others may feel shame, the belief that they have personally failed. In these cases, protesters demobilize and bystanders continue standing by: protests shrink in size. In addition, these emotions change individuals' risk aversion, perceived repression risk, and strategic consideration about other potential protesters, making individuals less likely to join a protest. (Young, 2019).

Emotions are especially useful for understanding how low amounts of repression can cause larger protests even when following no repression. If a protest at $t_{0}$ has $p_{0}$ participation and no repression, any repression at $t_{1}$ should cause $p_{1}<p_{0}$, ceteris paribus. But if repression induces feelings of anger, joy, or pride in more people than it creates fear, sadness, or shame, $p_{1}>p_{0}$. This backlash effect is in addition to any increase in size due to the first mechanism, difference in expectations. As Siegel (2011) shows:

Less obvious is that, if anger is strong enough, participation levels can be higher under repression than absent it. Individual anger at local repression endogenously enables aggregate backlash. Further, for weak repression, comparatively little anger is needed to achieve backlash against the repressive entity.

Emotions do not transform a calculating individual into an instinctual one. They do not 
replace calculation: they are inputs to that process.

Finally, we assume that a low level of repression triggers emboldening emotions while severe repression induces the dispiriting ones. If expectations and emotions influence protesters as described and the relationship between repression and triggered emotions follows the just stated assumption, then:

H1: There exists an $\mathrm{n}$-shaped relationship between the severity of state repression and the size of a protest the next day.

This relationship should hold in democracies and autocracies. For example, 2005 protests against chemical plants in Huashi, Zhejiang drew much greater participation after an initial attempt to remove protesters' encampments led to hundreds of injuries; authorities eventually closed the plants (O'Brien and Deng, 2015). The Occupy Wall Street movement in the United States experienced a surge in participants after New York City police arrested over 700 protesters marching on the Brooklyn Bridge, generating anger. In Egypt, the protests starting on January 25, 2011 were met with initial state resistance and some casualties; 18 days later, the Armed Forces forced President Hosni Mubarak to abdicate. Two years later, the Armed Forces launched a coup against the elected president, Mohamed Morsi. Large pro-Morsi protests erupted and continued for six weeks. The Armed Forces' initial attempts to demobilize them were counterproductive; finally, morning massacres on August 14 at the two main encampments killed at least 1,000 protesters, injured even more, and heralded the return of military rule (Shakir, 2014). ${ }^{3}$

$\overline{3}$ The expectation of backlash conditional on repression severity is consistent with Francisco (2004)'s argument for a strictly positive relationship between the two. Backlash in that theory encompasses nonprotest actions such as strikes, building occupations, or guerrilla action and allows for this substitution to occur much later (Moore, 2000). The tests of that backlash theory also find protesters initially demobilize in response to severe repression, in line with this paper's argument. 


\section{Protester Violence}

Protesters can also engage in violence, so a theory of protest dynamics should take their action into account. Protester violence should always decrease the size of protests for two reasons: it decreases the number of bystanders to whom protesting appeals and increases the cost of protesting to the remaining bystanders not deterred by protester violence.

One method by which bystanders determine whether to mobilize is to compare protesters' ideological distance to their own (Lohmann, 1994). Since most individuals do not support violence or receive consumption value from it (Muñoz and Anduiza, 2019, Simpson, Willer and Feinberg, 2018), protester violence signals that protesters, and therefore the policy changes for which they agitate, are likely not near the median policy preference. Being far from the mainstream, bystanders continue to stand by because the new policy the violent protesters seek is inferred to not reflect non-protesters' preferred policy.

Protester violence decreases the likelihood of regime defections, further decreasing the pool of potential protesters. Peaceful protest convinces regime agents of their physical safety should they defect, increasing the probability that police, members of the armed forces, or legislators switch allegiances (Stephan and Chenoweth, 2008). Violent protesters, however, induce fear in these agents that they will meet the same fate if they do not remain loyal. Violence therefore reduces the pool of those willing to protest, making the state stronger than if facing an otherwise equivalent peaceful protest.

Protests containing protester violence are seen as less legitimate than peaceful ones (Bashir et al., 2013), increasing the probability of repression and therefore the cost of protest. Peaceful protests enjoy high domestic and international legitimacy, so state violence against them risks generating a backlash that increases subsequent protests' size. But since the state can frame violent protesters as rioters, terrorists, or foreign agitators (Benford and Snow, 2000), bystanders are more supportive of repressing violent protests than nonviolent ones (Murdie and Purser, 2017). For the same reasons, the state is also less likely to receive international sanction when repressing violent protests. 
Conversely, protester non-violence increases the probability that a protest grows in size, especially when states repress. Because non-violence increases the legitimacy of protests, it decreases the probability that a state represses, as the state will pay large reputation costs. The lower probability of repression induces more bystanders to mobilize, generating a positive feedback loop (Biggs, 2003). In Morocco, for example, attempts to repress nonviolent protesters at the start of the Arab Spring led to larger crowd sizes (Lawrence, 2017), and government violence in Tunisia did not prevent the spread of those protests.

Since protester violence alienates bystanders and potential regime defectors and increases the cost of protesting, it should be that:

H2: There exists a negative relationship between the severity of protester violence and the size of a protest the next day.

\section{Methodology}

Research finds that state repression decreases protest (Moore, 2000, Olzak, Beasley and Olivier, 2003), increases it (Davenport and Armstrong II, 2004, Gurr and Moore, 1997, Hess and Martin, 2006), or has no effect (Gupta, Singh and Sprague, 1993, Ritter and Conrad, 2016). While this paper is not the first to suggest repression severity generates an n-shaped relationship, previous studies have relied on coarse measures such as ordinal variables or annual number of political detainees at the country level. By generating a more precise measure of the severity of repression, this paper resolves these contradictory findings.

Since the effect of state violence should vary based on its severity, precise measures of it are required, and image analysis enables this precision in two ways. First, convolutional neural networks will generate continuously valued estimates from $[0,1]$. Current leading datasets, by contrast, map violence onto different discrete categories (values of an ordinal variable). For example, the Social Conflict Analysis Database (SCAD), Urban Social Disorder, and Armed Conflict Locations and Event Data (ACLED) datasets record repression as a binary variable (Raleigh et al., 2010, Salehyan et al., 2012, Urdal and Hoelscher, 2012). Repression elsewhere 
is coded as ordinal or nominal, (Goldstein, 1992, Stephan and Chenoweth, 2008, Clark and Regan, 2016), including in machine-coded event data (Boschee et al., 2015). Second, whether one text, e.g. a newspaper article, shows that a protest is violent will depend on the written language used and the research teams' interpretation of that language. Researchers thus necessarily have to use coarse measures for large-n analysis. The closest continuously valued measure of repression is fatalities, which is not always recorded and is the most severe type of state violence. When focusing on violence in one setting, scholars have been more successful at disambiguating it to generate ordinal measures (Khawaja, 1993, Olivier, 1991).

This paper develops three classifiers based on convolutional neural networks to automatically code the variables of interest: one identifies protest images, a scene classifier extracts data from them, and a face classifier generates size estimates and demographic controls. ${ }^{4}$

The pipeline outlined in Table 1 resembles the approach described in Zhang and Pan (2019). Steps 1 uses keywords, including hard negatives like "concert" or "stadium", and Google Image Search to acquire training images. Step 2 then trains a CNN on these images. Steps 3 uses this classifier to identify protest images from just under 43 million geolocated tweets, resulting in 40,764 protest images. In Step 4, workers from Amazon Mechanical Turk label these Twitter images. To measure state and protester violence, annotators are presented pairs of images and asked which is more violent, and the Bradley-Terry model generates continuous estimates from the resulting ordering (Bradley and Terry, 1952). Each image is coded by at least two individuals; a third is used to break ties. These labels then train the second classifier (Step 5), and this classifier provides the estimates for state and protester violence. Separately, in Step 6, a third classifier assigns gender and age estimates to identified faces (Kärkkäinen and Joo, 2019); the count of faces provides an estimate of

$\overline{4}$ The first two classifiers are in fact partially combined in implementation such that one integrated classifier can generate two sets of outputs, although they differ conceptually. This is called multi-task learning (Girshick, 2015). We discuss two classifiers separately because they are trained on different data and used in different steps. 
protest size, and the demographic estimates generate control variables. These steps result in 40,764 tweets with new data about the demographics of individuals and severity and type of violence recorded in each image.

Figure 1 shows sample images of protest (top), state violence (middle), and protester violence (bottom) the pipeline identifies. For an overview of CNNs, see Section S1. Section $\mathrm{S} 2$ provides additional detail on our pipeline and validation of the results. Section S3 shows manual validation from a team of research assistants specifically trained for this project.

Table 1: Protest Data Pipeline

\begin{tabular}{|c|c|c|c|}
\hline Steps & Input & Source & Output \\
\hline \multicolumn{4}{|c|}{ Collecting Images for Training Set } \\
\hline 1. Image search & Keywords & Google & 100,000 images \\
\hline 2. Train a protest image classifier & Images from Step 1 & Self & Initial CNN \\
\hline $\begin{array}{l}\text { 3. Protest images from Twitter cor- } \\
\text { pus }\end{array}$ & Model from Step 2 & Twitter & 40,764 images \\
\hline \multicolumn{4}{|c|}{ Developing Protest and Scene Classifier } \\
\hline 4. Manual annotation & Images from Step 3 & $\begin{array}{l}\text { Amazon Mechanical } \\
\text { Turk }\end{array}$ & $\begin{array}{l}13 \text { ground-truth } \\
\text { labels }\end{array}$ \\
\hline 5. Train a CNN & Training data from Step 4 & Self & $\begin{array}{l}\text { Protest and } \\
\text { scene classifier }\end{array}$ \\
\hline \multicolumn{4}{|c|}{ Face Attribute Classification } \\
\hline 6. Face classification & - & $\begin{array}{l}\text { Kärkkäinen and Joo } \\
\text { (2019) }\end{array}$ & $\begin{array}{l}\text { Gender, age, and } \\
\text { size estimates }\end{array}$ \\
\hline
\end{tabular}

Note: The protest data pipeline encompasses six primary steps. Section S2 provides more detail.

\section{Data}

We identify five protest periods from polities with diverse population, income, and institutional characteristics, mitigating the risk that subsequent findings arise from underlying similarities in the cases. These polities are Hong Kong, Pakistan, South Korea, Spain, and Venezuela. The primary criteria is to construct a sample from different types of regimes, which we measure with the Polity4 score. Hong Kong has a score of -4; Venezuela, 4, Pakistan, 7, South Korea, 8, and Spain 10. We also consulted the Varieties of Democracy dataset to ensure these countries contain different media environments (e_v2xme_altinf_5C) and civil society freedom (e_v2xcs_ccsi_5c). With varying amounts of freedom of assembly, the 
(a) Protest
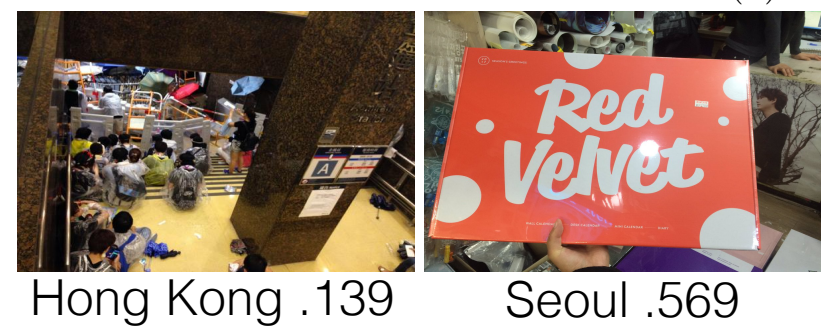

Seoul .569

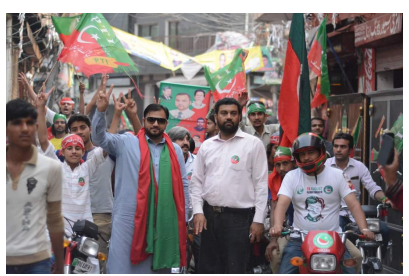

Lahore .884

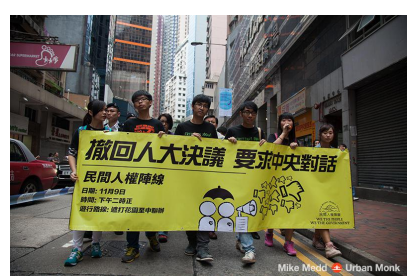

Hong Kong .957

(b) State Violence

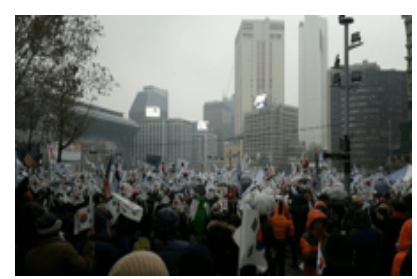

Seoul .031

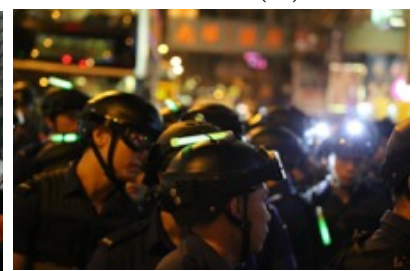

Hong Kong .145

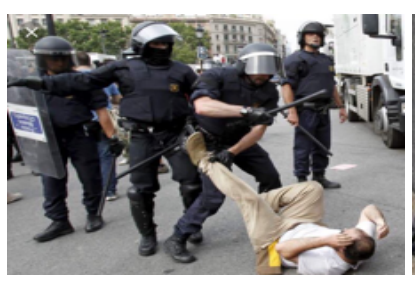

Barcelona .654

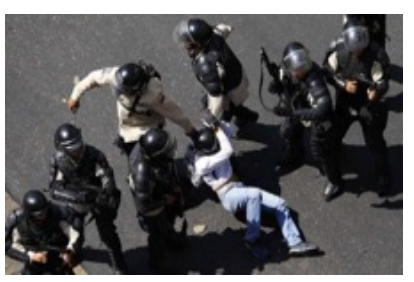

Caracas .849

(c) Protester Violence

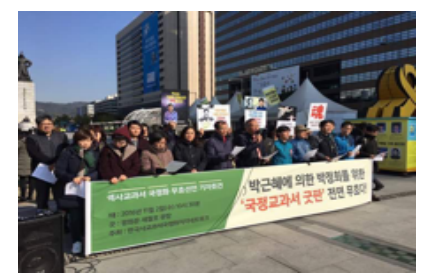

Seoul .021

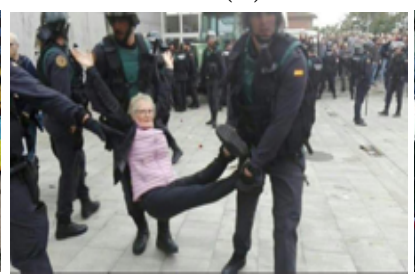

Barcelona .255

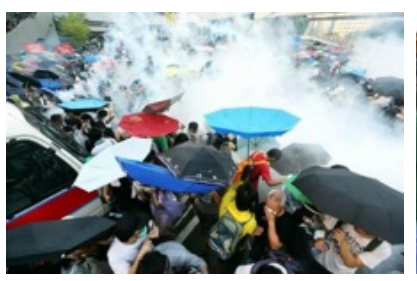

Hong Kong .478

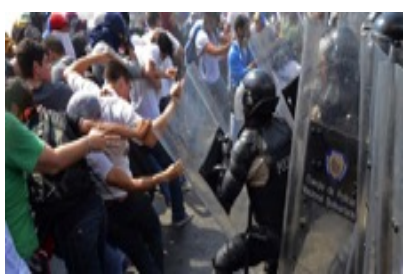

Caracas .998

Note: The top panel shows sample images and the protest classifier's rating of them. The use of hard negatives in the training set ensures that scenes that contain crowds (bottom row, left), individuals walking on streets (top row, third), or a non-protest sign (bottom row, third) are not included in analysis. The middle panel shows protest images with their state violence rating and the bottom shows protest images' protester violence rating. Labels contain each image's city and label probability.

press, and civil society, studying these countries minimizes, though it does not eliminate, the possibility that results derive from case selection.

Table 2 details the cities included from these countries, the issues driving protest, and the frequency of protest images per city. For each period, we searched from one week prior to the first reported protest and one week after the last one. This process identifies 42,579,188 tweets containing 4,456,981 images. Keeping only tweets whose images generate a protest score of at least .849 results in 26,142 tweets with images. ${ }^{5}$ These tweets are the data used

\footnotetext{
$5 \quad$ This threshold is the value which maximizes recall with .85 precision.
} 
for regressions.

We then aggregate tweets to their city of origin and the day they were created. Cities are kept for analysis when at least $\frac{1}{7}$ of their days contain a protest image. Table 2 shows these 24 cities, which account for 6,303 protest images. (Most images do not have a location resolution more precise than the country.) These 6,303 protest images spread across 4,143 city days. We treat missing dates as true zeroes, and a robustness check shows that this interpolation does not change results. Some of these images are duplicates, but later deduplication shows they do not affect inference.

Using these data introduces two ethical concerns. First, it is possible that minors are part of this study, as Twitter does not perform age verification for accounts and minors could appear in others' photos. Though many protests, such as Hong Kong's protests or the 2019 protests in Chile, feature prominent actors under the age of 18, we have only used faces from individuals estimated to be at least 20 years old. Second, protesters may not be as anonymous as they think. Though these data are observational and publicly available, individuals in photographs may not have consented to appear in those photographs. Authorities could monitor images shared on social media to identify people who protested; many already do (Purdy, 2018). ${ }^{6}$ To prevent the identification of individuals in our data, we have released only the aggregated city-day data.

\section{Operationalization}

The dependent variable is $\log _{10}(\text { Protest } S i z e)_{i, t}$, the logarithm of the sum of the number of faces in all protest photos from city $i$ on day $t$. Because the resulting numbers are certainly lower than the true protest size (the largest protest in our dataset contains 627 faces), five checks are performed to provide confidence that this operationalization actually measures protest dynamics. The estimates generated are consistent with others' and record actual events.

$6 \quad$ At the same time, however, shared protest images can identify incriminating state behavior that would otherwise be denied (Lim, 2013). 
Table 2: Protest Periods

\begin{tabular}{|c|c|c|c|c|c|c|c|}
\hline & City & Country & Start & End & Issue & Protest Images/Day & $\begin{array}{r}\text { Protest Images/Day } \\
\text { if }>0\end{array}$ \\
\hline 1 & Central & Hong Kong & 2014.09.18 & 2014.12 .23 & China reforms & 1.96 & 5.00 \\
\hline 2 & Kowloon & Hong Kong & 2014.09.18 & 2014.12 .23 & China reforms & 1.29 & 2.92 \\
\hline 3 & Lahore & Pakistan & 2017.11.07 & 2017.11.23 & Blasphemy & .18 & 1 \\
\hline 4 & Kimhae & South Korea & 2016.10.20 & 2017.03.14 & Anti-incumbency & .47 & 1.92 \\
\hline 5 & Seoul & South Korea & 2016.10 .20 & 2017.03.14 & Anti-incumbency & 2.40 & 3.76 \\
\hline 6 & Citutat Vella & Spain & 2017.09.01 & 2017.12.31 & Secession & .94 & 4.95 \\
\hline 7 & Barcelona & Spain & 2017.09.01 & 2017.12.31 & Secession & 3.07 & 11.60 \\
\hline 8 & Girona & Spain & 2017.09.01 & 2017.12.31 & Secession & 1.10 & 3.26 \\
\hline 9 & Granera & Spain & 2017.09.01 & 2017.12.31 & Secession & .62 & 2.33 \\
\hline 10 & Granollers & Spain & 2017.09.01 & 2017.12.31 & Secession & .23 & 1.25 \\
\hline 11 & Lleida & Spain & 2017.09.01 & 2017.12.31 & Secession & .42 & 1.88 \\
\hline 12 & Mataro & Spain & 2017.09.01 & 2017.12.31 & Secession & .51 & 2.33 \\
\hline 13 & Reus & Spain & 2017.09.01 & 2017.12.31 & Secession & .35 & 1.68 \\
\hline 14 & Sabadell & Spain & 2017.09.01 & 2017.12.31 & Secession & .96 & 2.66 \\
\hline 15 & St. Cugat d. Valles & Spain & 2017.09.01 & 2017.12.31 & Secession & .31 & 2.06 \\
\hline 16 & St. Feliu d. Pallerols & Spain & 2017.09.01 & 2017.12.31 & Secession & .61 & 2.19 \\
\hline 17 & St. Salvador d. Guardiola & Spain & 2017.09.01 & 2017.12.31 & Secession & .48 & 2.15 \\
\hline 18 & Tarragona & Spain & 2017.09.01 & 2017.12.31 & Secession & .57 & 1.94 \\
\hline 19 & Terrassa & Spain & 2017.09.01 & 2017.12.31 & Secession & .57 & 2.22 \\
\hline 20 & Boca del Rio & Venezuela & 2014.03 .27 & 2017.12.17 & Anti-Maduro & .26 & 1.34 \\
\hline 21 & Caracas & Venezuela & 2014.03 .27 & 2017.12.17 & Anti-Maduro & 4.82 & 7.63 \\
\hline 22 & Caucagua & Venezuela & 2014.03.27 & 2017.12.17 & Anti-Maduro & .53 & 1.72 \\
\hline 23 & Maracaibo & Venezuela & 2014.03 .27 & 2017.12.17 & Anti-Maduro & .39 & 1.49 \\
\hline 24 & Valencia & Venezuela & 2014.03 .27 & 2017.12.17 & Anti-Maduro & .41 & 1.62 \\
\hline
\end{tabular}

Note: The last column is the average number of photos for days containing a protest photo. 
The first check manually validates the face counts per photo. To complement the manual validation from Amazon Mechanical Turk that Figures A3 through A5 show, we trained a team of three students to count faces in images and label whether they contain state or protester violence; we then compare their coding to our classifier's estimates. The number of faces the human coders identify closely matches the classifier's face count, and images humans label that contain state or protester violence receive much higher classifier estimates for those labels than those that do not. Section S3 presents measures of intercoder reliability, and Figure A10 shows this comparison.

Second, size estimates for large protests could be biased upwards if the number of images and faces per image increases with protest size. Figure A11 shows no linear relationship between the size of a protest and the number of faces per photo. City-days with larger protests are therefore driven by the production of more protest images, not the sharing of crowded images. This result matches other work finding that counting faces in protest images generates accurate estimates of protest size variation (Sobolev et al., 2020).

Next, we consult other sources' estimates of protest size in Barcelona, Caracas, Seoul, and Hong Kong. For Caracas, we use crowd density estimates of protest images from Venezuelan newspapers (Rodríguez, 2020); this methodology is used widely because it generates accurate estimates of large crowds without directly counting every participant (McPhail and McCarthy, 2004). ${ }^{7}$ For Barcelona and Hong Kong, we trained a team of undergraduates to follow the coding procedure and sources of Weidmann and Rod (2018). That approach did not generate enough size estimates for Seoul, so we use police and activist size reports provided by Wikipedia. ${ }^{8}$ Table 3 shows this correlation for matched events and the results of two residual tests. Though higher correlations are preferable, the residual plots of Figure A12 show that $\log _{10}(\text { Protest Size })_{i, t}$ is not biased as a function of the protest size recorded

$7 \quad$ We also tried the Mass Mobilization in Autocracies dataset (Weidmann and Rod, 2018), but it recorded numeric estimates of protest size for only four events. Correlation with those is greater than .9 .

8 https://ko.wikipedia.org/wiki/박근혜_대통령_퇴진_운동 
in other sources. $\log _{10}(\text { Protest Size })_{i, t}$ is therefore a noisy but consistent estimate of protest size available from other sources. ${ }^{9}$

Table 3: Verifying Protest Size Estimate Using Other Sources

\begin{tabular}{lccccc} 
City & Source & Matched Events & Correlation & S-W & K-S \\
\hline \hline Barcelona & AFP, BBC, AP & 5 & .7980 & .0397 & .4714 \\
Caracas & Rodríguez (2020) & 18 & .4101 & .5975 & .7974 \\
Hong Kong & AFP, BBC, AP & 11 & .3477 & .8135 & .7967 \\
Seoul & Wikipedia: Police & 12 & .3686 & .7294 & .8785 \\
Seoul & Wikipedia: Activists & 21 & .4349 & .0491 & .7121 \\
\hline
\end{tabular}

Note: Taking the log of the sum of faces in protest photos correlates with logged estimates from newspapers (Barcelona, Hong Kong), Wikipedia (Seoul), and crowd density estimates (Caracas). The S-W column shows the p-value from the Shapiro-Wilks test, and the K-S column is for the Kolmogorov-Smirnov test; both are conducted on the residuals from regressing $\log _{10}(\text { Protest Size })_{i, t}$ on the log of the reported protest size. Lahore is not shown because we found no newspaper estimates of protest size from there.

Fourth, this pipeline recovers a very large percentage of protests identified in other event datasets for these countries, as Table 4 shows. The top rows show the number of city-days with protest observed using geolocated images for each city, region, or country. These records are compared to three leading event datasets; in each cell, the number is the number of events that dataset records and the percentage is the percent of those this methodology captures. These results are in line with what Zhang and Pan (2019) finds for Sina Weibo in China: their protest detection pipeline finds $52 \%$ of the events ICEWS does, $56 \%$ of GDELT's, and $88 \%$ of WiseNews. Note as well that most events we record are not recorded in the other event datasets, in line with similar comparisons in Chile, China, and Venezuela (Steinert-Threlkeld and Joo, 2020, Steinhardt and Goebel, 2019). ${ }^{10}$

Finally, the temporal variation of protest size is consistent with actual events. Figure 2 shows this result: the correspondence is consistent and appears to be more than chance. We $9 \quad$ These other sources are not used for size estimates because they contain too many false negatives.

10 These two articles do provide exact comparisons but show that social media generates data on many more events than MMAD or ICEWS in Venezuela, about the same as many as ACLED in Chile, and much more than domestic and international organizations in China. 
Table 4: Verifying Protest Coverage Using Other Event Data Source Catalonia Hong Lahore, South Venezuela Data Kong Pakistan Korea

\begin{tabular}{llccccc}
\hline \hline Images & Twitter & 1,421 & 137 & 17 & 232 & 2,336 \\
\hline ACLED & $\begin{array}{l}\text { Local \& international } \\
\text { news; reports. }\end{array}$ & - & - & $9,33 \%$ & - & - \\
ICEWS & $\begin{array}{l}\text { Local \& international } \\
\text { news }\end{array}$ & $54,94 \%$ & $49,59 \%$ & $2,0 \%$ & $99,82 \%$ & $365,49 \%$ \\
MMAD & AFP, BBC, AP & - & $105,91 \%$ & - & - & $4,100 \%$ \\
\hline
\end{tabular}

Note: The top row is the number of events in the Twitter data used for regressions. Each subsequent row shows (\# events in dataset, \% match with Twitter); for example, ICEWS records 54 events in Catalonia, $94 \%$ of which the Twitter data contain. All ICEWS events with a city of 'nan' are dropped. MMAD contains more events from Hong Kong here than in Table 3 because this table does not restrict events to those with size estimates.

did not attempt to label every peak, but other work has found that social media records protests at least as well as other event datasets (Dowd et al., 2020).

The violence variables to test Hypothesis 1 are Perceived State Violence $e_{i, t-1}$ and its square. For H2, Perceived Protester Violence $e_{i, t-1}$. These are the average of the classifier estimate for all protest images per city-day. Figure A13 in Section S5 shows a time series of the mean state violence recorded in protest images for the same four cities.

We describe the violence variables as "perceived" for three reasons. First, the true amount of violence is unknown because violence is a latent concept, not a physical entity, like temperature or pressure, directly measurable. Second, the images people share may be strategically chosen. This possible selection effect is true of any event data that relies on secondary sources, which is to say almost all event data. For discussion and analysis of bias that these measures may introduce, see Section S8. Third, the main analysis does not deduplicate images, meaning images which are shared often will have a greater impact on people's decision making process than those only tweeted once. Deduplicating images to more closely approximate the "true" violence at events does not change results, as Table 6 shows. 
Figure 2: Verifying Protest Size, Time Series

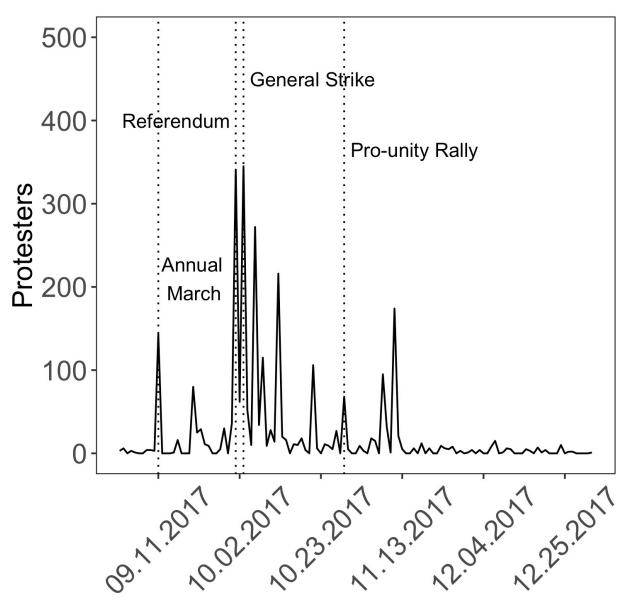

(a) Barcelona

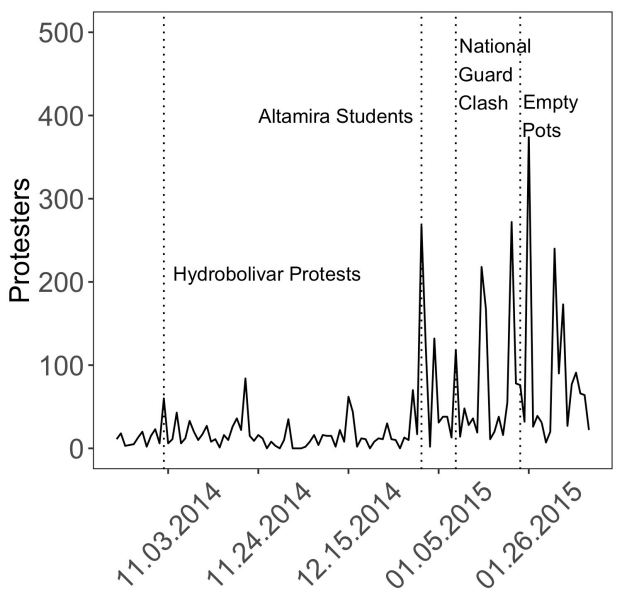

(c) Caracas

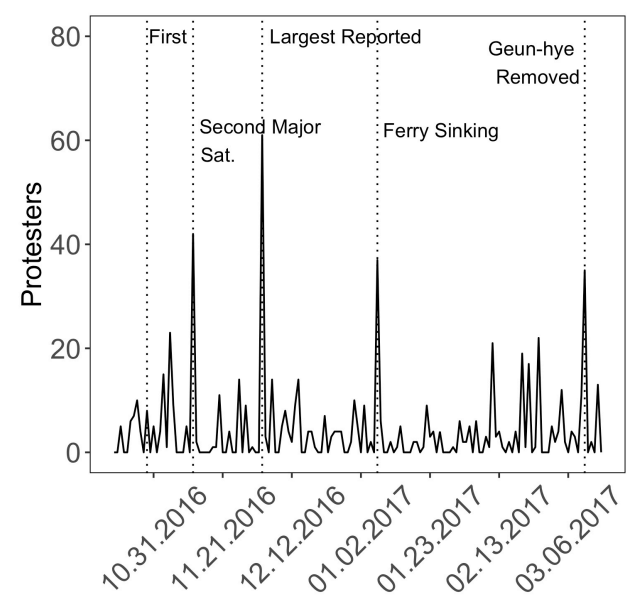

(b) Seoul

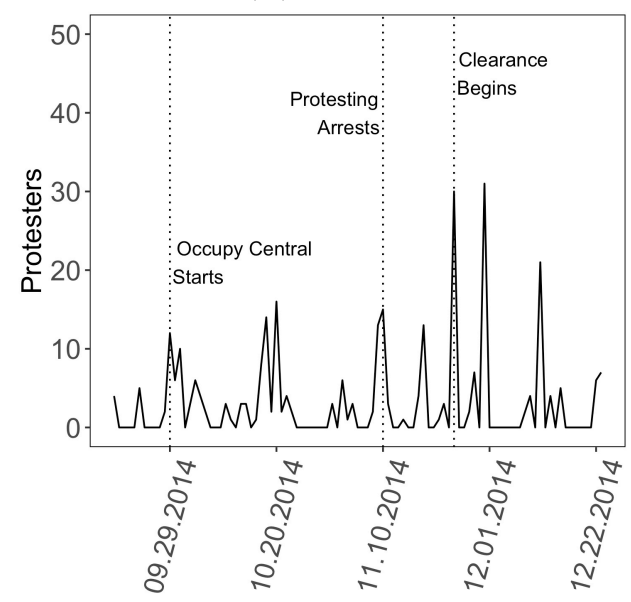

(d) Hong Kong

Note: Measuring protest size using faces in images records changes in protest size that match reported dynamics.

\section{Model}

In addition to the operationalizations detailed in the previous section, we include six control variables. Two are demographic: the gender and age attributes of protesters. A society with greater gender equality is more likely to see nonviolent than violent action (Schaftenaar, 2017), and the same is true at the movement level (Asal et al., 2013). The percent of protesters who are male, Male Percent $t_{i, t-1}$, is therefore a variable for which we control. Since youth often spearhead mass protests and these effects are amplified when there are many of them, 
the percent of participants aged 20-29, Young Adult Percent ${ }_{i, t-1}$, is a variable for which we control (González, 2020, Urdal, 2006). ${ }^{11}$

We also generate two binary variables, Police $_{i, t-1}$ and Fire $_{i, t-1}$. The police and fire variables are the sum of images containing a police officer or fire, respectively, based on the thresholds identified in Table A2. Police $_{i, t-1}$ provides another estimate of repression, while Fire $_{i, t-1}$ approximates protester violence (Figure A14 shows that fire and protester violence have the highest city-day correlation of any two variables). Fifth, Tweet $s_{i, t-1}$ is the number of lagged protest images per country-day and controls for any protest information not directly measured, such as tactical knowledge about a protest (Little, 2015). Sixth, we include a lagged dependent variable to account for autocorrelation as well as any regression to the mean. Table 5 provides descriptive statistics of these variables.

Table 5: Summary Statistics for Regression Variables

\begin{tabular}{lccccc} 
Statistic & N & Mean & St. Dev. & Min. & Max. \\
\hline \hline Protest Size $_{i, t}$ & 4,143 & 2.57 & 15.36 & 0 & 627 \\
Perceived Protester Violence $_{i, t-1}$ & 4,121 & 0.03 & 0.12 & 0.00 & 1.00 \\
Perceived State Violence $_{i, t-1}$ & 4,121 & 0.02 & 0.08 & 0.00 & 0.94 \\
Police $_{i, t-1}$ & 4,121 & 0.001 & 0.04 & 0.00 & 1.00 \\
Fire $_{i, t-1}$ & 4,121 & 0.08 & 0.42 & 0.00 & 7.00 \\
Male Percent $_{i, t-1}$ & 4,121 & 0.03 & 0.11 & 0.00 & 1.00 \\
Young Adult Percent $_{i, t-1}$ & 4,121 & 0.02 & 0.08 & 0.00 & 1.00 \\
Tweets $_{i, t-1}$ & 4,121 & 1.52 & 7.02 & 0.00 & 238.00 \\
\hline
\end{tabular}

Note: Summary statistics for the regression variables.

We build three models. The first uses only covariates that measure violence. The second focuses on the demographic control variables. The final model combine the two sets of variables. All independent variables are lagged one day. All models include city fixed effects and city-clustered standard errors. To guard against overfitting, we use five-fold cross-validation. Ordinary least squares is the estimator.

1120 is the the oldest age of legal adulthood (Japan) of which we are aware, so we use it to be cautious. 


\section{Results}

Results match expectations: low amounts of state violence correlate with larger subsequent protests $(p<.001)$, though severe enough violence with subsequently smaller protests $(p<$ .001). When protesters engage in violence, recorded subsequent protest size is smaller $(p<$ .05). In addition, protester violence has a much smaller coefficient than either state violence variable, with the largest magnitude occurring when states engage in high levels of violence. Table A5 in Section S7 shows these results.

Figure 3 shows marginal effects of state and protester violence from that model. From values of [0-.3), state violence correlates with larger subsequent protest. At that amount of violence, protest size the next day is $137 \%$ higher than if there was no state violence. Moreover, state repression usually leads to larger protests: only 77 of 1,467 city-days of protest contain average state violence greater than .3. Increased protester violence always correlates with subsequently smaller protest. The change, however, is much smaller than for state violence: moving from no protester violence to its mean (.035) correlates with a $2 \%$ smaller protest, while the difference between state violence and its mean is an increase of just over $17 \%$. A one standard deviation increase of state violence from 0 correlates with a

$63 \%$ increase in protest size; a one standard deviation increase in protester violence from zero correlates with a $12 \%$ smaller protest.

\section{Robustness Checks}

A series of robustness checks on state violence confirms its n-shaped relationship with subsequent protest size. First, images with more violence could contain fewer faces, causing the regression results to be driven by measurement problems. While lagging the independent variables mitigates this concern, Figure 4 shows that no relationship appears to exist between the violence an image records and the number of faces contained therein. To the extent that one does, it is actually slightly positive, biasing against finding a negative relationship. Second, the n-shaped relationship between state violence and the next day's protest size could 
Figure 3: Marginal Effects

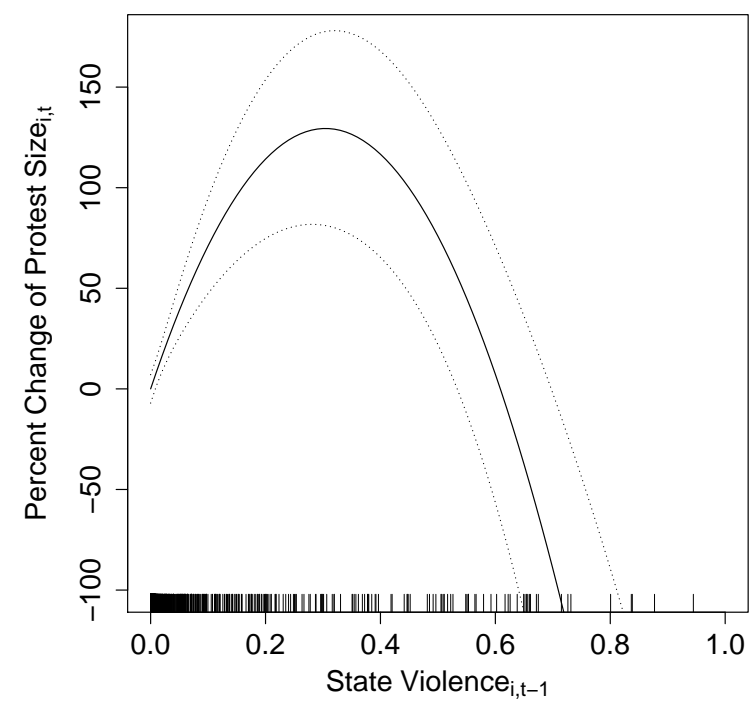

(a) State Violence

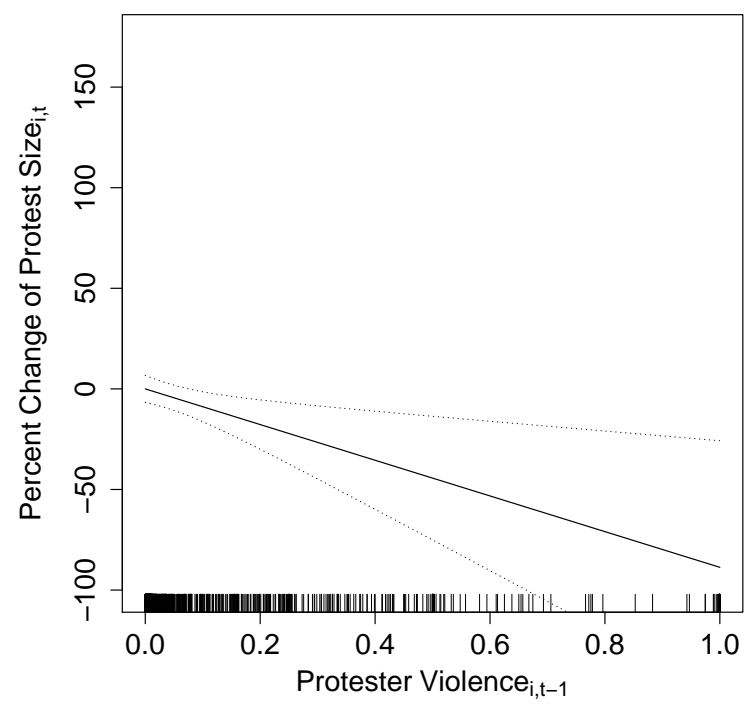

(b) Protester Violence

Note: Marginal effects of Perceived State Violence $_{i, t-1}$ and Perceived Protester Violence $_{i, t-1}$ from Model 3 of Table A5. State violence exhibits an n-shaped relationship with subsequent protest size while protester violence always correlates with smaller subsesquent protests.

be an artifact of fitting a parametric model with a square term. Figure 5 shows the results of tests demonstrating the persistence of this relationship. Whether fitting a local average of the relationship between Perceived State Violence $_{i, t-1}$ and $\log _{10}(\text { Sum of Faces })_{i, t}$ or a spline with 50 knots, binning Perceived State Violence $_{i, t-1}$ into ten evenly spaced groups, or regressing Perceived State Violence $_{i, t-1}$ on partial residuals, the n-shaped relationship between state violence and subsequent protest size holds.

Strategic behavior of protesters and state agents may endogenously cause the observed correlations. Protesters often seek international attention because it increases their legitimacy and raises the cost of repression (Bruns, Highfield and Burgess, 2013), and protesters are strategic about the language in which they make these appeals (Driscoll and SteinertThrelkeld, 2020, Metzger, Nagler and Tucker, 2015). These appeals may downplay protester violence and exaggerate the size of protests. To deter protester coordination, state actors will emphasize protester and state violence as well as downplay the size of crowds. 
Figure 4: State Violence Does Not Cause Fewer Faces per Photo

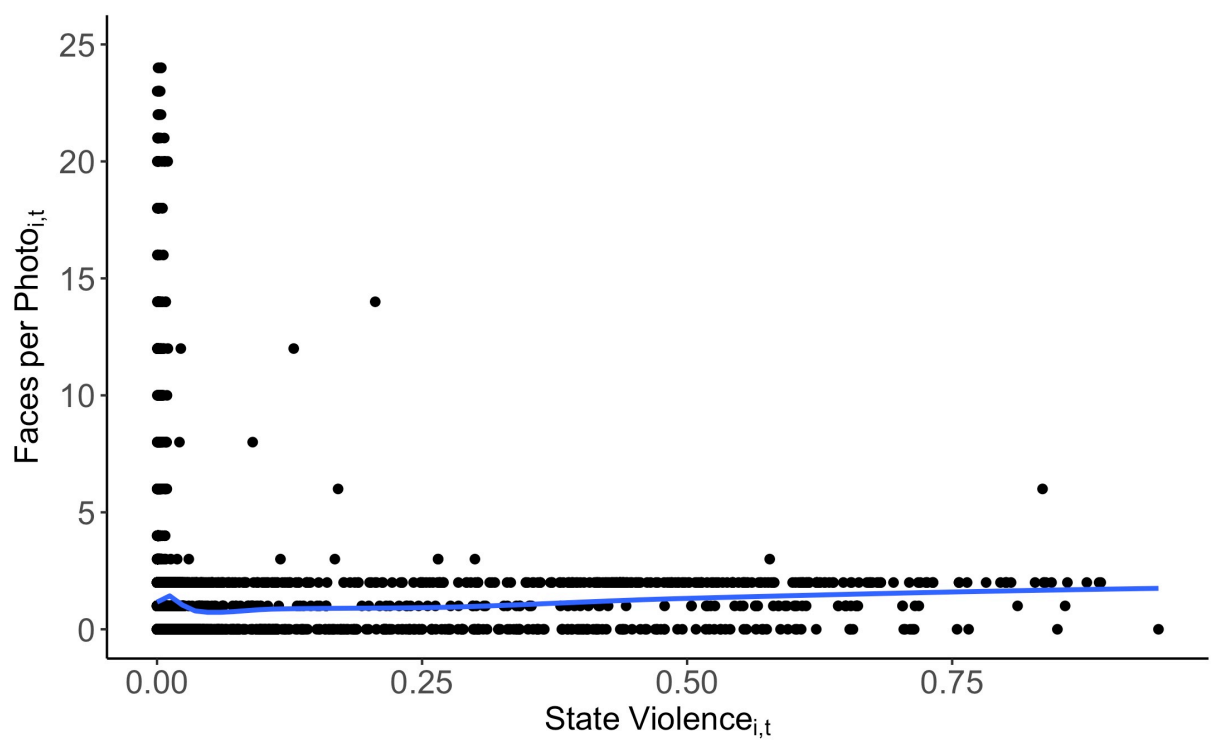

Note: No correlation exists between state violence in an image and the number of faces. A linear fit suggests a slight positive relationship, and restricting the relationship to images with fewer than ten faces does not change results. 
Figure 5: State Violence Results Remain in Flexible Operationalizations

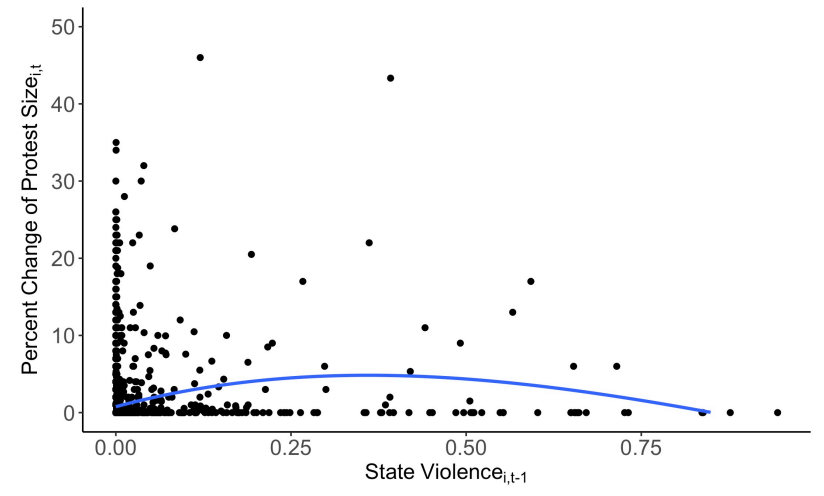

(a) $\operatorname{LOESS}(\operatorname{Span}=.2)$

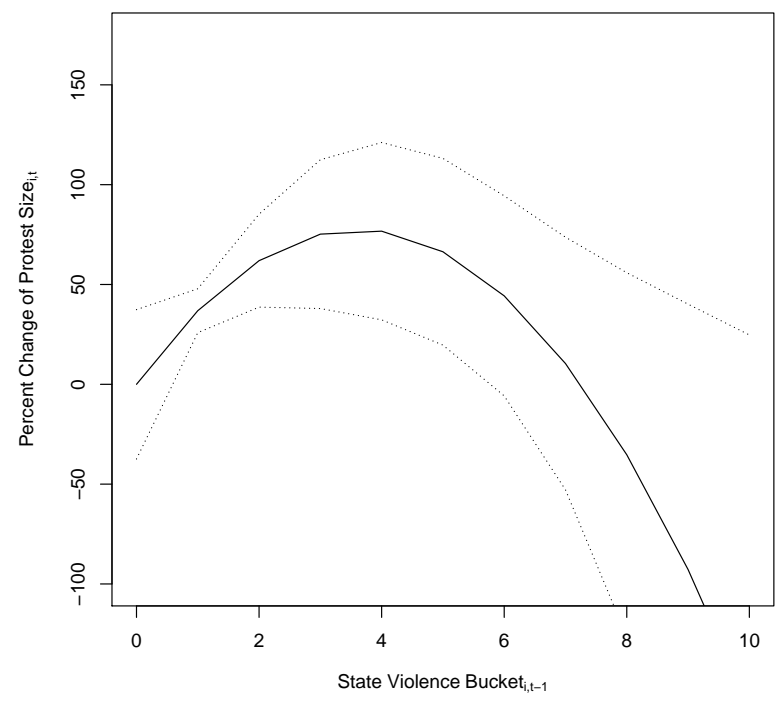

(c) Binned Marginal Effects

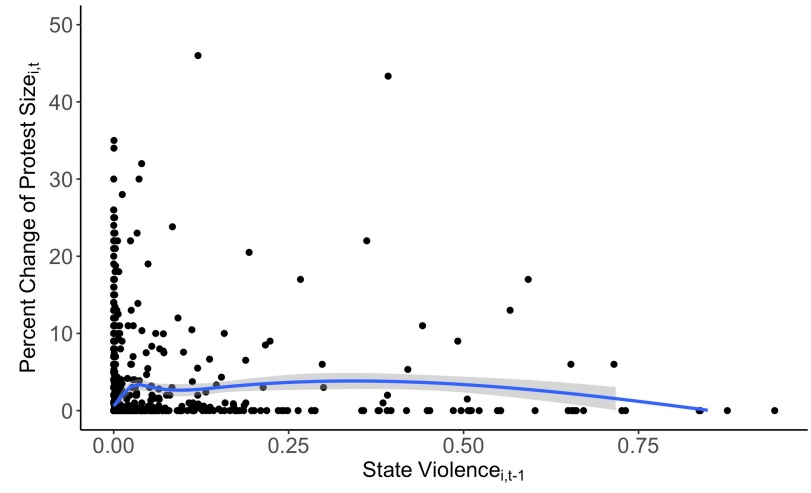

(b) Spline, 50 Knots

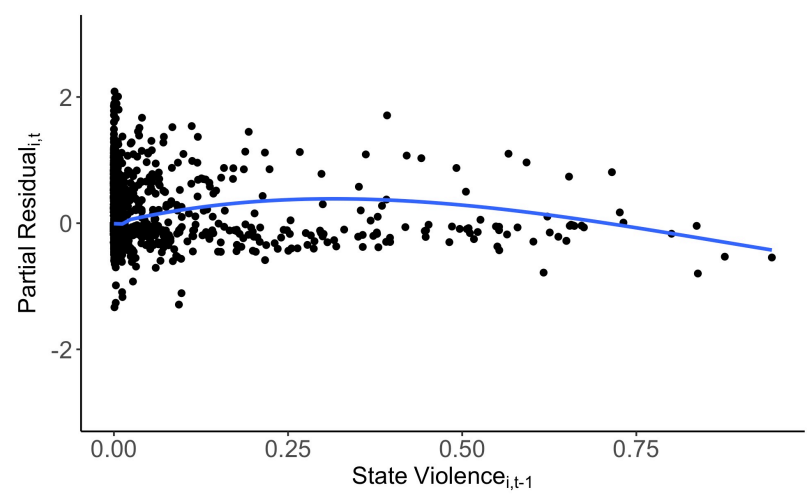

(d) LOESS on Partial Residuals

Note: The n-shaped relationship holds in a non-parametric relationship (a, b). Generating fixed effects for state violence in bins of width of .1 finds the same relationship (c). Regressing state violence on the partial residuals of Model 3 from Table A5. 
Table 6 shows that tests for this strategic behavior do not change inference. Model 1 restricts analysis to those tweets in the country's lingua franca, as they are the ones most relevant for local actors. Model 2 drops tweets from bots (accounts controlled by computer code) since actors use them to strategically amplify messages. ${ }^{12}$ Since strategic actors may emphasize particular protest features by repeatedly sharing photos, Model 3 keeps only the first occurrence of an image. ${ }^{13}$ Strategic actors are also more likely to have very many followers (authority figures) or very few (bots), so Model 4 restricts analysis to only tweets from accounts within the $25^{t h}-75^{t h}$ percentile of their country's follower distribution. Model 5 focuses on attempts to manipulate estimates of protest size by making the dependent variable equal the logarithm of the number of unique accounts that share protest images. This new dependent variable is not affected by images chosen for the number of protesters they show or strategic actors tweeting frequently.

Across all models save the last, the results for state violence stay the same; Model 5 also records an n-shaped relationship, but the coefficient on the squared term is too small to be statistically significant. (Table A8 shows that the raw number of users recreates the n-shaped relationship.) Inferences about protester violence also do not change except for one model, Model 3; its sign is still the same, and results weighted by the number of tweets per city-day (Table A9) make the variable significant again.

Finally, Table 7 shows that accounting for more complicated time dynamics does not change inferences about state violence, though it weakens the negative correlation of protester violence and subsequent protest size. A partial autocorrelation plot suggests 15 lags of the

12 We submit every user to the Botometer service and remove tweets with a complete automation probability $\geq .4$, the threshold which that produces the most accurate classification of bots (Varol et al., 2017). Table A13 shows that no more than $10.8 \%$ of tweets in any city are from bots.

13 The data do not contain retweets because Twitter does not assign coordinates to retweets. They contain replies, and replies contain the image of the original tweet. Section S11 explains the deduplication methodology, and Table A14 show the percent of tweets per city that are duplicates. 
Table 6: Robust to Strategic Behaviors

\begin{tabular}{|c|c|c|c|c|c|}
\hline & $\begin{array}{c}\text { Country } \\
\text { Language } \\
(1) \\
\end{array}$ & $\begin{array}{l}\text { No } \\
\text { Bots } \\
(2) \\
\end{array}$ & $\begin{array}{l}\text { Deduplicated } \\
\text { Images } \\
(3) \\
\end{array}$ & $\begin{array}{l}\text { IQR } \\
\text { Users } \\
(4) \\
\end{array}$ & $\begin{array}{c}\text { DV: } \\
\log _{10}\left(\text { Number of } U \operatorname{ser} s_{i, t}\right) \\
(5)\end{array}$ \\
\hline Perceived Prtstr. Violence $e_{i, t-1}$ & $\begin{array}{c}-.1982^{* * *} \\
(.0387)\end{array}$ & $\begin{array}{c}-.1438^{* *} \\
(.0704)\end{array}$ & $\begin{array}{l}-.1301 \\
(.0853)\end{array}$ & $\begin{array}{c}-.1530^{* * *} \\
(.0446)\end{array}$ & $\begin{array}{c}-.1784^{* * *} \\
(.0495)\end{array}$ \\
\hline Perceived Stt. Violence $e_{i, t-1}$ & $\begin{array}{c}1.5665^{* * *} \\
(.4553)\end{array}$ & $\begin{array}{c}1.2236^{* * *} \\
(.3349)\end{array}$ & $\begin{array}{c}1.2138^{* *} \\
(.5284)\end{array}$ & $\begin{array}{c}1.1894^{* * *} \\
(.3333)\end{array}$ & $\begin{array}{l}.3938^{*} \\
(.2340)\end{array}$ \\
\hline Perceived Stt. Violence ${ }_{i, t-1}^{2}$ & $\begin{array}{c}-2.5718^{* * *} \\
(.8864)\end{array}$ & $\begin{array}{c}-2.0184^{* * *} \\
(.5787)\end{array}$ & $\begin{array}{c}-2.0015^{* *} \\
(.9100)\end{array}$ & $\begin{array}{c}-2.0125^{* * *} \\
(.5509)\end{array}$ & $\begin{array}{l}-.6597 \\
(.4044)\end{array}$ \\
\hline Police $_{i, t-1}$ & $\begin{array}{l}.5070 \\
(.3090)\end{array}$ & $\begin{array}{l}.6357^{*} \\
(.3712)\end{array}$ & $\begin{array}{l}.9419^{*} \\
(.5190)\end{array}$ & $\begin{array}{l}.8552^{* *} \\
(.3763)\end{array}$ & $\begin{array}{l}.2250 \\
(.2720)\end{array}$ \\
\hline Fire $_{i, t-1}$ & $\begin{array}{l}.0753^{* * *} \\
(.0249)\end{array}$ & $\begin{array}{l}.0912^{* * *} \\
(.0202)\end{array}$ & $\begin{array}{c}.0594 \\
(.0507)\end{array}$ & $\begin{array}{l}.0576^{*} \\
(.0316)\end{array}$ & $\begin{array}{c}.0667^{* * *} \\
(.0152)\end{array}$ \\
\hline Male Percent $_{i, t-1}$ & $\begin{array}{l}-.0617 \\
(.1264)\end{array}$ & $\begin{array}{l}-.1848^{*} \\
(.1078)\end{array}$ & $\begin{array}{l}-.0833 \\
(.1201)\end{array}$ & $\begin{array}{l}-.0195 \\
(.0458)\end{array}$ & $\begin{array}{c}-.1068^{* *} \\
(.0543)\end{array}$ \\
\hline Young Adult Percent $t_{i, t-1}$ & $\begin{array}{l}.0173 \\
(.0845)\end{array}$ & $\begin{array}{l}.2166^{* *} \\
(.0905)\end{array}$ & $\begin{array}{l}.2848^{* *} \\
(.1370)\end{array}$ & $\begin{array}{l}.2584^{* * *} \\
(.0953)\end{array}$ & $\begin{array}{l}.1162^{* *} \\
(.0466)\end{array}$ \\
\hline Tweets $_{i, t-1}$ & $\begin{array}{l}.0249^{* * *} \\
(.0047)\end{array}$ & $\begin{array}{l}.0119^{* *} \\
(.0047)\end{array}$ & $\begin{array}{l}.0162^{* *} \\
(.0069)\end{array}$ & $\begin{array}{l}.0148^{* *} \\
(.0060)\end{array}$ & $\begin{array}{l}.0037^{*} \\
(.0021)\end{array}$ \\
\hline $\mathrm{DV}_{i, t-1}$ & $\begin{array}{l}.1145 \\
(.0772)\end{array}$ & $\begin{array}{l}.1766^{* *} \\
(.0782)\end{array}$ & $\begin{array}{l}.1490^{*} \\
(.0844)\end{array}$ & $\begin{array}{l}.1047^{* * *} \\
(.0363)\end{array}$ & $\begin{array}{l}.4062^{* * *} \\
(.1004)\end{array}$ \\
\hline Intercept & $\begin{array}{l}.0694^{* * *} \\
(.0138)\end{array}$ & $\begin{array}{l}.1186^{* * * *} \\
(.0157)\end{array}$ & $\begin{array}{l}.1319^{* * *} \\
(.0172)\end{array}$ & $\begin{array}{l}.1270^{* * *} \\
(.0160)\end{array}$ & $\begin{array}{l}.1027^{* * *} \\
(.0105)\end{array}$ \\
\hline $\mathrm{N}$ & 3,481 & 4,121 & 2,533 & 3,462 & 4,121 \\
\hline Adjusted $\mathrm{R}^{2}$ & .3144 & .2732 & .2223 & .1897 & .4125 \\
\hline Cluster SE & $\mathrm{Y}$ & $\mathrm{Y}$ & $\mathrm{Y}$ & $\mathrm{Y}$ & Y \\
\hline City FE & $\mathrm{Y}$ & Y & Y & Y & $\mathrm{Y}$ \\
\hline
\end{tabular}

${ }^{*} \mathrm{p}<.1 ;{ }^{* *} \mathrm{p}<.05 ;{ }^{* * *} \mathrm{p}<.01$

Model 1 keeps only tweets in each country's lingua franca. Model 2 drops all tweets from accounts identified as bots. Model 3 removes duplicate images. Model 4 keeps only tweets from users within the interquartile range of their country's follower distribution. Model 5's dependent variable is the logarithm transformation of the number of users tweeting protest images. Standard errors are clustered by city.

dependent variable, which Model 1 includes. Model 2 includes weekend fixed effects, and Model 3 includes weekday ones. Model 4 includes a control for the protest duration and the number of consecutive days of state repression. In all specifications, the n-shaped relationship of state violence and subsequent protest remains statistically significant. Models 1 and 4 no longer find significant results for protester violence, suggesting that protesters may become more violent the longer a protest lasts. Model 4 also shows that protests decrease in size over time, though persistent state violence correlates with larger protests.

Section S8 presents two checks of the data generating process to address concerns about selection bias. Users who share protest images may differ from those who share non-protest 
Table 7: Time Effects Do Not Change Results

\begin{tabular}{|c|c|c|c|c|}
\hline & \multicolumn{4}{|c|}{ DV: $\log _{10}(\text { Sum of Faces })_{i, t}$} \\
\hline & 15 Lags & $\begin{array}{l}\text { Weekend } \\
\text { FE }\end{array}$ & $\begin{array}{l}\text { Weekday } \\
\text { FE }\end{array}$ & $\begin{array}{l}\text { Duration } \\
\text { Controls }\end{array}$ \\
\hline & (1) & $(2)$ & $(3)$ & $(4)$ \\
\hline Perceived Prtstr. Violence ${ }_{i, t-1}$ & $\begin{array}{l}-.0366 \\
(.0831)\end{array}$ & $\begin{array}{c}-.1543^{*} \\
(.0830)\end{array}$ & $\begin{array}{c}-.1571^{*} \\
(.0831)\end{array}$ & $\begin{array}{l}-.0489 \\
(.0775)\end{array}$ \\
\hline Perceived Stt. Violence $_{i, t-1}$ & $\begin{array}{l}.7348^{* *} \\
(.3226)\end{array}$ & $\begin{array}{c}1.2716^{* * *} \\
(.3722)\end{array}$ & $\begin{array}{c}1.2864^{* * *} \\
(.3727)\end{array}$ & $\begin{array}{l}.8831^{* * *} \\
(.3283)\end{array}$ \\
\hline Perceived Stt. Violence ${ }_{i, t-1}^{2}$ & $\begin{array}{c}-1.2775^{* *} \\
(.5291)\end{array}$ & $\begin{array}{c}-2.0853^{* * *} \\
(.6515)\end{array}$ & $\begin{array}{c}-2.1055^{* * *} \\
(.6528)\end{array}$ & $\begin{aligned}- & 1.5302^{* * *} \\
& (.5435)\end{aligned}$ \\
\hline Police $_{i, t-1}$ & $\begin{array}{l}.6381^{*} \\
(.3864)\end{array}$ & $\begin{array}{l}.7512 \\
(.4584)\end{array}$ & $\begin{array}{l}.7553^{*} \\
(.4570)\end{array}$ & $\begin{array}{l}.5867^{*} \\
(.3391)\end{array}$ \\
\hline Fire $_{i, t-1}$ & $\begin{array}{l}.0229 \\
(.0334)\end{array}$ & $\begin{array}{l}.0995^{* * *} \\
(.0360)\end{array}$ & $\begin{array}{l}.0998^{* * *} \\
(.0360)\end{array}$ & $\begin{array}{l}.0127 \\
(.0313\end{array}$ \\
\hline Male Percent $_{i, t-1}$ & $\begin{array}{c}-.1952^{* * *} \\
(.0735)\end{array}$ & $\begin{array}{c}-.1805^{* *} \\
(.0734)\end{array}$ & $\begin{array}{c}-.1789^{* *} \\
(.0731)\end{array}$ & $\begin{array}{c}-.1800^{* * *} \\
(.0674)\end{array}$ \\
\hline Young Adult Percent ${ }_{i, t-1}$ & $\begin{array}{l}.2127^{*} \\
(.1093)\end{array}$ & $\begin{array}{l}.1930^{*} \\
(.1030)\end{array}$ & $\begin{array}{l}.1927^{*} \\
(.1032)\end{array}$ & $\begin{array}{l}.1575 \\
(.1009)\end{array}$ \\
\hline Tweets $_{i, t-1}$ & $\begin{array}{l}.0059^{* * *} \\
(.0021)\end{array}$ & $\begin{array}{l}.0088^{* * *} \\
(.0030)\end{array}$ & $\begin{array}{l}.0087^{* * *} \\
(.0031)\end{array}$ & $\begin{array}{l}.0055^{* * *} \\
(.0020)\end{array}$ \\
\hline $\mathrm{DV}_{i, t-1}$ & $\begin{array}{l}.0864^{* * *} \\
(.0308)\end{array}$ & $\begin{array}{l}.1998^{* * *} \\
(.0352)\end{array}$ & $\begin{array}{l}.2002^{* * *} \\
(.0352)\end{array}$ & $\begin{array}{l}.1141^{* * *} \\
(.0294)\end{array}$ \\
\hline Protest Days $i, t$ & & & & $\begin{array}{c}-.0006^{* * *} \\
(.0001)\end{array}$ \\
\hline Consec. Stt. Violence ${ }_{i, t}$ & & & & $\begin{array}{l}.0638^{* * *} \\
(.0064)\end{array}$ \\
\hline Intercept & $\begin{array}{l}.0278^{* *} \\
(.0130)\end{array}$ & $\begin{array}{c}.1161^{* * *} \\
(.0184) \\
\end{array}$ & $\begin{array}{l}.1260^{* * *} \\
(.0218)\end{array}$ & $\begin{array}{c}.2655^{* * *} \\
(.0271)\end{array}$ \\
\hline $\mathrm{N}$ & 3,777 & 4,121 & 4,121 & 4,121 \\
\hline Adjusted $\mathrm{R}^{2}$ & .3489 & .2684 & .2686 & .3505 \\
\hline Cluster SE & $\mathrm{Y}$ & $\mathrm{Y}$ & $\mathrm{Y}$ & $\mathrm{Y}$ \\
\hline City FE & $\mathrm{Y}$ & $\mathrm{Y}$ & $\mathrm{Y}$ & $\mathrm{Y}$ \\
\hline
\end{tabular}

${ }^{*} \mathrm{p}<.1 ;{ }^{* *} \mathrm{p}<.05 ;{ }^{* * *} \mathrm{p}<.01$

The n-shaped relationship of state violence and subsequent protest size holds when controlling for time dynamics. Protest Days $i, t$ refers to the length of a protest, and Consec. Stt. Violence $i, t$ the number of consecutive days of state violence.

images; Figure A15 shows, and t-tests confirm, these users do not differ. Users may strategically choose the level of geographic specificity to assign to a tweet depending on the tweet content. Figure A16 shows the distribution of estimates for number of faces and perceived state and protester violence by country and four levels of geographic specificity. Most tweets are with neighborhood or city specificity, and the classifier results do not systematically vary 
by geographic level within a country.

Section S9 presents nine additional robustness checks. Section S9.1 performs the same non-parametric examinations of Perceived Protester Violence $_{i, t-1}$ that were performed on Perceived State Violence $_{i, t-1}$. Section S9.2 presents the results from a vector autoregression, the results of which are consistent with Table 7. Section S9.3 aggregates tweets to their state or country to see if individuals selecting the tweet's geographic level biases results. Section S9.4 confirms that modeling days without protest images as days of no protest does not affect results. Section S9.5 shows that different transformations of the dependent variable do not change results. Section S9.6 weights city-days by number of tweets and their inverse; results do not change, suggesting these findings are not an artifact of Twitter prevalence in certain locales. Section S9.7 analyzes tweets most likely to originate at a protest: those from mobile phones or during protest hours. Section S9.8 shows results controlling for tweets about protest but without images. Section S9.9 disaggregates results by country. In all models, the protester and state violence variables exhibit the same relationships found in the other results, though protester violence's coefficient occasionally becomes close enough to zero to be indistinguishable from it. ${ }^{14}$

\section{Discussion}

The results presented here suggest that state violence generates an n-shaped correlation with subsequent protest size while protester violence is consistently negative. While emphasizing the severity of repression during protest policing is not new (Khawaja, 1993, Muller, 1985), measuring non-lethal repression as a continuous variable is. This insight is not measurable without applying recent advances in computer vision to large datasets of individual behavior, in this case geolocated images shared on Twitter.

Synthesizing this paper's results with others' suggests protest dynamics work as follows. Preventative repression, such as arresting a group's leaders or seizing their offices, makes it harder for protests to start (Danneman and Ritter, 2013, Sutton, Butcher and Svensson, 2014,

$\overline{14}$ We also reran the main model but with $\log \left(\right.$ Tweet $_{i, t-1}$, The results do not change. 
Sullivan, 2016). Once started, protester violence decreases support for protest and therefore its subsequent size (Wasow, 2020). Repression produces differential effects depending on its severity: light state violence generates backlash while severe state violence "works".

Future research should focus on several areas. It is possible that when in a protest cycle repression occurs correlates with its severity; future work should interact state violence with when in a protest cycle that violence occurs. Mechanisms connecting state and protester violence to changes in protest size also require investigation; emotions can be measured from social media text and images (Steinert-Threlkeld and Joo, 2020), and expectations can be measured with longitudinal surveys (Cantoni et al., 2019). In addition, global event datasets could be constructed using this methodology. An advantage of using images is that they are closer to a universal language than text (Graber, 1996). Classifiers generated from images are therefore less context dependent than text ones, so they can be applied across settings and time periods. For more detail on the advantages of images for generating protest event data, see Steinert-Threlkeld (2019).

Social media make valuable contributions to understanding subnational conflict. Metzger, Nagler and Tucker (2015) and Driscoll and Steinert-Threlkeld (2020) use social media as a quasi-poll to understand mass protests in Ukraine. Steinert-Threlkeld (2017) shows that coordinating activity correlates with more protests when that activity comes less influential members of society. Larson et al. (2019) studies 130,000,000 protesters in France, finding that protesters are embedded in denser social networks than bystanders. Muchlinski et al. (2020) measures electoral violence using CNNs and tweets. Social media, moreover, often generates more extensive records of protest than wire reports or newspapers, the primary source for existing event datasets (Steinert-Threlkeld and Joo, 2020, Steinhardt and Goebel, 2019). These data are not a fad or detached from reality: they offer unprecedented insights into human behavior and should continue to grow in importance to political science research.

If a picture is worth 1,000 words, then it would require approximately two kilobytes of storage (Jagenstedt, 2008). Images from consumer cell phones and digital cameras, however, 
require at least three megabytes of storage, usually more. Even images shared on social media platforms, which are compressed from their original size, require hundreds of kilobytes of space. A picture, in other words, is worth anywhere from 50,000 (100 kilobytes) to 1,500,000 words (3 megabytes). ${ }^{15}$ A picture is actually worth a book, and there are vast libraries waiting to be explored.

$\overline{15}$ This estimate is poetic. Another way to think of images is that they have high entropy, meaning they cannot be compressed as much as text. The greater size of images reflects this greater difficulty of compressing them, not necessarily a true quantum of information. 
Acknowledgments. We would like to thank the editor and three reviewers for their excellent and punctual feedback. Justin Jerro, Xiaofeng Lin, Jun Luo, Jack Schafer, Donghyeon Won, and Cindy Yuan provided essential research assistance. Alexei Abrahams, Konstantin Ash, Michael Chwe, Emilio Ferrara, Tim Groeling, Susan Hyde, Jason Jones, Andrew Little, Susanne Lohmann, Brandon Merrell, Tamar Mitts, David Muchlinski, Kevin O'Brien, Jennifer Pan, Margaret Roberts, Jacob Shapiro, Joshua Tucker, Austin Wright, Nils Weidmann, Thomas Zeitzoff, and Yuri Zhukov have provided valuable feedback throughout. Comments at APSA, EPSA, IC2S2, ISA, Peace Science, Politics and Computational Social Science, Political Methodology, and SPSA also refined the paper. Research costs money, and support from the NSF (SBE-SMA \#1831848), California Center for Population Research, and internal UCLA grants made this work possible. All remaining errors are unintentional. 


\section{References}

Asal, Victor, Richard Legault, Ora Szekely and Jonathan Wilkenfeld. 2013. "Gender ideologies and forms of contentious mobilization in the Middle East." Journal of Peace Research $50(3): 305-318$.

Bashir, Nadia Y., Penelope Lockwood, Alison L. Chasteen, Daniel Nadolny and Indra Noyes. 2013. "The ironic impact of activists: Negative stereotypes reduce social change influence." European Journal of Social Psychology 43(7):614-626.

Battaglini, Marco. 2017. "Public Protests and Policy Making." Quarterly Journal of Economics 132(1):485-549.

Benford, Robert D. and David A. Snow. 2000. "Framing Processes and Social Movements: An Overview and Assessment." Annual Review of Sociology 26:611-639.

Biggs, Michael. 2003. "Positive feedback in collective mobilization: The American strike wave of 1886." Theory and Society 32:217-254.

Boschee, Elizabeth, Jennifer Lautenschlager, Sean O’Brien, Steve Shellman, James Starz and Michael Ward. 2015. "ICEWS Coded Event Data." http://dx.doi.org/10.7910/DVN/28075 .

Bradley, Ralph Allan and Milton E Terry. 1952. "Rank analysis of incomplete block designs: I. The method of paired comparisons." Biometrika 39(3/4):324-345.

Bratton, Michael and Nicolas Van De Walle. 1992. "Popular Protest and Political Reform in Africa." Comparative Politics 24(4):419-442.

Bruns, Axel., T. Highfield and J. Burgess. 2013. "The Arab Spring and Social Media Audiences: English and Arabic Twitter Users and Their Networks." American Behavioral Scientist 57(7):871-898. 
Bueno de Mesquita, Bruce, Alastair Smith, Randolph M. Siverson and James D. Morrow. 2003. The Logic of Political Survival. Cambridge: MIT Press.

Cantoni, Davide, David Y. Yang, Noam Yuchtman and Y. Jane Zhang. 2019. "Protests as Strategic Games: Experimental Evidence from Hong Kong's Anti-Authoritarian Movement." The Quarterly Journal of Economics 134(2):1021-1077.

Clark, David H. and Patrick M. Regan. 2016. "Mass Mobilization." https://www.binghamton.edu/massmobilization/about.html .

Danneman, Nathan and Emily H. Ritter. 2013. "Contagious Rebellion and Preemptive Repression." Journal of Conflict Resolution 58(2):254-279.

Davenport, Christian. 2007. "State Repression and Political Order." Annual Review of Political Science 10(1):1-23.

Davenport, Christian and David A. Armstrong II. 2004. "Democracy and the Violation of Human Rights: A Statistical Analysis from 1976 to 1996." American Journal of Political Science 48(3):538-554.

DeNardo, James. 1985. Power in Numbers: The Political Strategy of Protest and Rebellion. Princeton: Princeton University Press.

Dowd, Caitriona, Patricia Justino, Roudabeh Kishi and Gauthier Marchais. 2020. "Comparing 'New' and 'Old' Media for Violence Monitoring and Crisis Response in KEnya." Research and Politics 7(3):1-9.

Downs, Anthony. 1957. An Economic Theory of Democracy. New York City: Harper and Row.

Driscoll, Jesse and Zachary C. Steinert-Threlkeld. 2020. "Social media and Russian territorial irredentism: some facts and a conjecture conjecture." Post-Soviet Affairs 36(2):101-121. 
Earl, Jennifer, Heather McKee Hurwitz, Analicia Mejia Mesinas, Margaret Tolan and Ashley Arlotti. 2013. "This Protest Will Be Tweeted: Twitter and protest policing during the Pittsburgh G20." Information, Communication \& Society 16(4):459-478.

Francisco, Ronald A. 2004. "After the Massacre: Mobilization in the Wake of Harsh Repression." Mobilization: An International Journal 9(2):107-126.

Girshick, Ross. 2015. Fast r-cnn. In Proceedings of the IEEE international conference on computer vision. pp. 1440-1448.

Goldstein, Joshua S. 1992. "A Conflict-Cooperation Scale for WEIS Events Data." Journal of Conflict Resolution 36(2):369-385.

González, Felipe. 2020. "Collective action in networks: Evidence from the Chilean student movement." Journal of Public Economics 188:104220.

Graber, Doris A. 1996. "Say It with Pictures." The ANNALS of the American Academy of Political and Social Science 546(1):85-96.

Gupta, Dipak K., Harinder Singh and Tom Sprague. 1993. "Government Coercion of Dissidents: Deterrence or Provocation?" Journal of Conflict Resolution 37(2):301-339.

Gurr, Ted Robert and Will H. Moore. 1997. "Ethnopolitical Rebellion: A Cross-Sectional Analysis of the 1980s with Risk Assessments for the 1990s." American Journal of Political Science 41(4):1079-1103.

Hess, David and Brian Martin. 2006. "Repression, Backfire, and the Theory of Transformative Events." Mobilization: An International Journal 11(2):249-267.

Jagenstedt, Philip. 2008. "How much a thousand words are worth." https://blog.foolip.org/2008/05/17/how-much-a-thousand-words-are-worth/ .

Jasper, James M. 2011. "Emotions and Social Movements: Twenty Years of Theory and Research." Annual Review of Sociology 37(1):285-303. 
Kärkkäinen, Kimmo and Jungseock Joo. 2019. "FairFace: Face Attribute Dataset for Balanced Race, Gender, and Age." arXiv preprint arXiv:1908.04913 .

Khawaja, Marwan. 1993. "Repression and Popular Collective Action: Evidence from the West Bank." Sociological Forum 8(1):47-71.

Larson, Jennifer M, Jonathan Nagler, Jonathan Ronen and Joshua A Tucker. 2019. "Social Networks and Protest Participation: Evidence from 130 Million Twitter Users." American Journal of Political Science 63(3):690-705.

Lawrence, Adria K. 2017. "Repression and Activism among the Arab Spring's First Movers: Evidence from Morocco's February 20th Movement." British Journal of Political Science 47(3):699-718.

Lim, Merlyna. 2013. 'Framing Bouazizi: 'White lies', hybrid network, and collective/connective action in the 2010-11 Tunisian uprising." Journalism 14(7):921-941.

Little, Andrew T. 2015. "Communication Technology and Protest." Journal of Politics 78(1):152-166.

Lohmann, Susanne. 1994. "The Dynamics of Informational Cascades: The Monday Demonstrations in Leipzig, East Germany, 1989-91." World Politics 47(1):42-101.

McPhail, Clark and John McCarthy. 2004. "Who Counts and How: Estimating the Size of Protests." Contexts 3(3):12-18.

Metzger, Megan, Jonathan Nagler and Joshua a. Tucker. 2015. "Tweeting Identity? Ukrainian, Russian, and \#Euromaidan." Journal of Comparative Economics 44(1):16-40.

Moore, Will H. 2000. "The Repression of Dissent: A Substitution Model of Government Coercion." Journal of Conflict Resolution 44(1):107-127. 
Muchlinski, David, Xiao Yang, Sarah Birch, Craig MacDonald and Iadh Ounis. 2020. "We Need to Go Deeper: Measuring Electoral Violence using Convolutional Neural Networks and Social Media." Political Science Research and Methods pp. 1-18.

Muller, Edward N. 1985. "Income Inequality, Regime Repressiveness, and Political Violence." American Sociological Review 50(1):47-61.

Muñoz, Jordi and Eva Anduiza. 2019. "'If a fight starts, watch the crowd': The effect of violence on popular support for social movements." Journal of Peace Research 56(4):485498.

Murdie, Amanda and Carolin Purser. 2017. "How protest affects opinions of peaceful demonstration and expression rights." Journal of Human Rights 16(3):351-369.

Nordås, Ragnhild and Christian Davenport. 2013. "Fight the Youth: Youth Bulges and State Repression." American Journal of Political Science 57(4):926-940.

O’Brien, Kevin J. and Yanhua Deng. 2015. "Repression Backfires: tactical radicalization and protest spectacle in rural China." Journal of Contemporary China 24(93):457-470.

Olivier, Johan L. 1991. "State repression and collective action in South Africa, 1970 - 84." South African Journal of Sociology 22(4):109-117.

Olzak, Susan, Maya Beasley and Johan Olivier. 2003. "The Impact of State Reforms on Protest Against Apartheid in South Africa." Mobilization 8(1):27-50.

Pearlman, Wendy. 2013. "Emotions and the Microfoundations of the Arab Uprisings." Perspectives on Politics 11(02):387-409.

Purdy, Chase. 2018. "China is launching a dystopian program to monitor citizens in Beijing." https://qz.com/1473966/china-is-starting-a-big-brother-monitoring-program-in-beijing/ . 
Qin, Bei, David Strömberg and Yanhui Wu. 2017. "Why Does China Allow Freer Social Media? Protests Versus Surveillance and Propaganda." Journal of Economic Perspectives 31(1):117-140.

Raleigh, Clionadh, Andrew Linke, Havard Hegre and Joakim Karlsen. 2010. "Introducing ACLED: An Armed Conflict Location and Event Dataset: Special Data Feature." Journal of Peace Research 47(5):651-660.

Ritter, Emily Hencken and Courtenay R. Conrad. 2016. "Preventing and Responding to Dissent: The Observational Challenges of Explaining Strategic Repression." American Political Science Review 110(1):85-99.

Robertson, Graeme B. 2007. "Strikes and Labor Organization in Hybrid Regimes." American Political Science Review 101(04):781-798.

Rodríguez, Francisco. 2020. Things Fall Apart: Nicolás Maduro and the Unraveling of Venezuela's Populist Experiment 2012-2020. Unpublished Manuscript.

Salehyan, Idean, Cullen Hendrix, Jesse Hammer, Christina Case, Christopher Linebarger, Emily Stull and Jennifer Williams. 2012. "Social Conflict in Africa: A New Database." International Interactions 38(4):503-511.

Schaftenaar, Susanne. 2017. "How (wo)men rebel: Exploring the effect of gender equality on nonviolent and armed conflict onset." Journal of Peace Research 54(6):762-776.

Shadmehr, Mehdi and Dan Bernhardt. 2011. "Collective Action with Uncertain Payoffs: Coordination, Public Signals, and Punishment Dilemmas." American Political Science Review 105(04):829-851.

Shakir, Omar. 2014. All According to Plan: The Rab'a Massacre and Mass Killings of Protesters in Egypt. Technical report Human Rights Watch. 
URL: $\quad$ https://www.hrw.org/report/2014/08/12/all-according-plan/raba-massacre-andmass-killings-protesters-egypt

Siegel, David A. 2011. "When Does Repression Work? Collective Action in Social Networks." The Journal of Politics 73(04):993-1010.

Simpson, Brent, Robb Willer and Matthew Feinberg. 2018. "Does Violent Protest Backfire? Testing a Theory of Public Reactions to Activist Violence." Socius: Sociological Research for a Dynamic World 4:237802311880318.

Sobolev, Anton, Jungseock Joo, Keith Chen and Zachary C. Steinert-Threlkeld. 2020. "News and Geolocated Social Media Accurately Measure Protest Size Variation." American Political Science Review pp. 1-9.

Steinert-Threlkeld, Zachary C. 2017. "Spontaneous Collective Action: Peripheral Mobilization During the Arab Spring." American Political Science Review 111(02):379-403.

Steinert-Threlkeld, Zachary C. 2019. "Comment: The Future of Event Data is Images." Sociological Methodology 49.

Steinert-Threlkeld, Zachary C and Jungseock Joo. 2020. "Protest Event Data from Geolocated Social Media Content." APSA Preprints: https://doi.org/10.33774/apsa-2020-mjz4s

Steinhardt, H. Christoph and Christian Goebel. 2019. "Better coverage, less bias: Using social media to measure protest in authoritarian regimes." https://www.researchgate.net/publication/332112415_Better_coverage_less_bias_Using_ social_media_to_measure_protest_in_authoritarian_regimes .

Stephan, Maria J. and Erica Chenoweth. 2008. "Why Civil Resistance Works." International Security 33(1):7-44. 
Sullivan, Christopher M. 2016. "Political Repression and the Destruction of Dissident Organizations." World Politics 68(4):645-676.

Sutton, Jonathan, Charles R. Butcher and Isak Svensson. 2014. "Explaining political jiujitsu: Institution-building and the outcomes of regime violence against unarmed protests." Journal of Peace Research 51(5):559-573.

Tucker, Joshua A. 2007. "Enough! Electoral Fraud, Collective Action Problems, and PostCommunist Colored Revolutions." Perspectives on Politics 5(03):535.

Tullock, Gordon. 1971. "The Paradox of Revolution." Public Choice 11:89-99.

Urdal, Henrik. 2006. "A Clash of Generations? Youth Bulges and Political Violence." International Studies Quarterly 50:607-629.

Urdal, Henrik and Kristian Hoelscher. 2012. "Explaining Urban Social Disorder and Violence: An Empirical Study of Event Data from Asian and Sub-Saharan African Cities." International Interactions 38(4):512-528.

Varol, Onur, Emilio Ferrara, Clayton A. Davis, Filippo Menczer and Alessandro Flammini. 2017. "Online Human-Bot Interactions: Detection, Estimation, and Characterization." arXiv preprint arXiv:1703.0310v2 .

Wasow, Omar. 2020. "Agenda Seeding: How 1960s Black Protests Moved Elites, Public Opinion and Voting." American Political Science Review 114(3):638-659.

Weidmann, Nils B. and Espen Geelmuyden Rod. 2018. Coding Protest Events in Autocracies. In The Internet and Political Protest in Autocracies. Oxford University Press chapter Chapter 4.

Wouters, Ruud and Stefaan Walgrave. 2017. "Demonstrating Power: How Protest Persuades Political Representatives." American Sociological Review 82(2):361-383. 
Young, Lauren E. 2019. "The Psychology of State Repression: Fear and Dissent Decisions in Zimbabwe." American Political Science Review 113(1):140-155.

Zhang, Han and Jennifer Pan. 2019. "CASM: A Deep-Learning Approach for Identifying Collective Action Events with Text and Image Data from Social Media." Sociological Methodology 49:1-48.

Zhao, Dingxin. 1998. "Ecologies of Social Movements: Student Mobilization during the 1989 Prodemocracy Movement in Beijing." American Journal of Sociology 103(6):1493-1529. 
Biographical Statements. Zachary C. Steinert-Threlkeld is an assistant professor at UCLA, Los Angeles, CA 90095. Alexander Chan was a graduate research assistant at UCLA, Los Angeles, CA 90095 and is now an Infrastructure Data Scientist at Facebook. Jungseock Joo is an assistant professor at UCLA, Los Angeles, CA 90095. 